\title{
Fast Food Consumption, Quality of Diet, and Obesity among Isfahanian Adolescent Girls
}

\author{
Mohammad Hossein Rouhani, ${ }^{1,2}$ Maryam Mirseifinezhad, ${ }^{1,2}$ Nasrin Omrani, ${ }^{1,2}$ \\ Ahmad Esmaillzadeh, ${ }^{1,2}$ and Leila Azadbakht ${ }^{1,2}$ \\ ${ }^{1}$ Food Security Research Center, Isfahan University of Medical Sciences, Isfahan, Iran \\ ${ }^{2}$ Department of Community Nutrition, School of Nutrition and Food Science, Isfahan University of Medical Sciences, Isfahan, Iran
}

Correspondence should be addressed to Leila Azadbakht, azadbakht@hlth.mui.ac.ir

Received 2 January 2012; Revised 11 March 2012; Accepted 19 March 2012

Academic Editor: Jack A. Yanovski

Copyright (C) 2012 Mohammad Hossein Rouhani et al. This is an open access article distributed under the Creative Commons Attribution License, which permits unrestricted use, distribution, and reproduction in any medium, provided the original work is properly cited.

\begin{abstract}
Background and Objective. Few data are available linking fast food intake to diet quality in developing countries. This study was conducted to determine the association between fast food consumption and diet quality as well as obesity among Isfahani girls. Methods. This cross-sectional study was done among 140 Iranian adolescents selected by the use of systematic cluster random sampling. Dietary intakes were assessed using a validated food frequency questionnaire. Diet quality was defined based on energy density and nutrient adequacy ratios (NARs). Results. Individuals in the highest quartile of fast food intake had significantly lower NARs for vitamin $\mathrm{B}_{1}(P=0.008)$, phosphorus $(P=0.0250)$, selenium $(P<0.001)$ and vitamin $\mathrm{B}_{2}(P=0.012)$ compared with those in the lowest quartile. Those in top quartile of fast food intake consumed more energy-dense diets than those in the bottom quartile $(P=0.022)$. High intakes of fast foods were significantly associated with overweight (top quartile: $40 \%$ versus bottom quartile: $0 \%, P=0.0001)$ and obesity $(11.4 \%$ versus $2.9 \%, P=0.0001)$. Conclusion. Fast food consumption is associated with poor diet quality and high prevalence of overweight and obesity among Isfahani adolescents. Prospective data are required to confirm these findings.
\end{abstract}

\section{Introduction}

Obesity is a worldwide chronic disease which may lead to type 2 diabetes and cardiovascular diseases [1]. It is reported that 400 million adults are obese and 1.6 billion are overweight worldwide [2]. The prevalence of obesity and overweight among Iranian population was estimated to be $67 \%$ for women and 29\% for men [3]. Besides the high prevalence of obesity among adults, the prevalence of childhood obesity is also growing in an alarming rate. During three past decades, the prevalence of obesity among children and adolescents was doubled in the United States [4]. According to the results of a national study in Iran, the prevalence of overweight and obesity among Iranian children was $10.1 \%$ and $4.7 \%$, respectively, and approximately $10 \%$ of adolescents were overweight [5]. A recent report revealed that skipping breakfast, consuming unhealthy and high energy dense snack during school time, low level of physical activity, low socioeconomic status, and familial history of obesity were proposed factors regarding high prevalence of obesity among Iranian adolescent [6].

Nutrition transition is an important factor which can affect dietary intakes, particularly in developing countries [7]. The rate of processed foods consumption (e.g., fast foods) is going to be increased due to nutrition transition [8].

Fast foods are rich sources of saturated fatty acids and trans fatty acids [9]. Fast food consumption can lead to hyperinsulinemia and development of insulin resistance. High energy density, high glycemic index, and fatty acid composition of fast foods may increase the prevalence of obesity and cardiovascular risk factors [10]. Previous studies showed that fast food outlets availability particularly in school neighborhood is related to increased body mass index in students [11]. The rate of fast food consumption has been increased in past years specially among children and adolescents [12]. 
Previous studies revealed that fast food consumption accompanied with lower dietary quality [13]. According to the published papers, the diet quality of Iranian's needs to be improved [14]. Iranian traditional dietary pattern has high content of saturated fatty acids and refined carbohydrates [15]. Therefore, considering the associated factors to diet quality of Iranians is an important factor in the field of dietary researches in Iran.

The combination of traditional Iranian dietary pattern and nutritional transition provides a specific opportunity for more researches in the field of dietary intake in this country. There were some investigations in this topic among western population but epidemiological studies should be run in each population separately especially among the population of the Middle Eastern countries because of unique dietary habits [2].

Few studies were conducted to investigate the relationship between fast food consumption, dietary quality, and chronic disease in Middle Eastern region especially among Iranians.

So, in this study, we evaluated the relationship between fast food consumption, quality of diet, obesity, and central adiposity in a sample of Isfahani (the second big city of Iran) adolescents.

\section{Subjects and Methods}

2.1. Subjects. In this cross-sectional study, one hundred forty Isfahanian female students aged 11 to 13 years old are selected by the use of systematic cluster random sampling. In this study we randomly selected some regions from among all the regions of Isfahan. We tried to include different regions with different socioeconomic status in the present study. Then some schools were randomly chosen from selective regions. The list of students' records was obtained from each school and the students were randomly selected according to a computer-based random sequencing program.

All students were eligible to enter to this study unless they were on a specific diet. Finally, 140 adolescents completed the study. Written informed consent was taken from each student and one of her parents.

2.2. Dietary Assessment. Usual dietary intake was evaluated by self-administered semiquantitative FFQ which included 53 food items. The FFQ contained 8 fast foods items and it covered food intakes during last year. The reliability of this semiquantitative FFQ was evaluated in a randomly chosen subgroup of 92 adolescents by comparing nutrient consumption ascertained by FFQ responses on 2 occasions. The correlation coefficients for the repeatability of white bread, pizza, French fries, and red meat were 0.60, 0.59, 0.55, and 0.57 , respectively. The FFQ also had high reliability for nutrients. For example, the correlation coefficients were 0.61 for dietary protein, 0.60 for riboflavin, 0.61 for selenium, 0.53 for sodium, 0.64 for energy intake, and 0.63 for dietary fat. Comparative validity was determined by comparison of the values resulting from FFQ with intakes estimated from the average of three 24-h dietary records (one for weekend and two for week days). Preliminary analysis of the validation study showed that nutrients were moderately correlated (all correlation coefficients were $>0.5$ ) between these 2 methods after control for total energy intake. For example, it was 0.54 for protein, 0.53 for fat, 0.57 for vitamin $C$, and 0.52 for selenium. The performance of the FFQ in assessing the fast food intake also was fair. For example, between FFQ and detailed dietary recalls, correlation coefficients were 0.57 for pizza, 0.56 for French fries, and 0.60 for white bread. Overall, these data indicate that the FFQ provides reasonably valid measures of the average long-term dietary intake. A complete guideline along with several samples and descriptions were prepared and attached to the questionnaires. Trained nutritionists educated all the students and one of their parents in specific educational sessions to fill the FFQ. Parents were requested to help students in filling the FFQ. The reported amounts for each food was converted to a daily amount and mentioned as grams per day.

Fast foods were defined as following items: "convenience food" or prepared foods such as hamburger, sausage, cheese burger, other burgers, hot dogs, rusk fish, rusk poultry, French fries, and pizza.

Nutrient adequacy ratio (NAR) was calculated by dividing daily individual intake to dietary recommended intake (DRI) [16] for each nutrient.

To calculate dietary energy density we divided daily individual energy intake to total weight of foods (excluding beverages) consumed $(\mathrm{g} / \mathrm{kcal})$. Some data showed that the weight of drank beverages had not any role in the relationship between dietary energy density and body weight [17].

2.3. Anthropometric Assessment. Height was measured to the nearest $1 \mathrm{~cm}$ by meter in condition of standing position near to the wall, paired feet, removed shoes, and four contacted points of the body (shoulder, hip, heel, and head) to wall. Body weight was measured to the nearest $0.1 \mathrm{~kg}$ by standard scale in lightweight-clothed and no-shoes-using subjects. Waist circumference was measured to the nearest $0.1 \mathrm{~cm}$ by an inelastic tape, tangent to skin, and without any pressure. This measurement was conducted in narrowest girth, after a normal exhalation and with relaxed abdominal muscles. In standing position and paired feet, widest hip diagonal was measured [18]. Calculation of body mass index was performed as body weight in kilogram divided by height square in meters. Overweight and obesity were defined based on World Health Organization guidelines as BMI $=85$ th -95 th percentile and $>95$ th, respectively.

2.3.1. Assessment of Other Factors. data on general information including age, sex, history of diseases, and different medications use were collected by the use of questionnaires. The participants were asked to write their activities and duration of each activity within 3 days in a week (two working days and one holiday). Then the mean of physical activity was calculated using the following equation:

$$
\mathrm{PA}_{\text {mean }}=\sum\left(\frac{\text { Time }_{\text {activity }} \times \text { MET }}{72}\right),
$$

where $\mathrm{PA}_{\text {means }}$ is the mean of physical activity, Time activity is the total time (h) of each activity within 3 days (72 hours), 
TABle 1: Demographic characteristics across the quartiles of fast food consumption.

\begin{tabular}{|c|c|c|c|c|c|}
\hline \multirow[b]{2}{*}{ Variables } & \multicolumn{4}{|c|}{ Quartiles of fast food intake } & \multirow[b]{2}{*}{$P^{2}$} \\
\hline & $\begin{array}{c}\mathrm{Q}_{1} \\
{[<51.8 \mathrm{~g} / \text { week }] n=35}\end{array}$ & $\begin{array}{c}\mathrm{Q}_{2} \\
{[51.9-100.7 \mathrm{~g} / \text { week }]} \\
n=34\end{array}$ & $\begin{array}{c}\mathrm{Q}_{3} \\
{[100.8-214.9 \mathrm{~g} / \text { week }]} \\
n=36\end{array}$ & $\begin{array}{c}\mathrm{Q}_{4} \\
{[>215 \mathrm{~g} / \text { week }] n=35}\end{array}$ & \\
\hline Age (y) & $12.32 \pm 1.088^{1}$ & $12.58 \pm 0.89$ & $12.33 \pm 1.01$ & $12.42 \pm 0.88$ & 0.677 \\
\hline Height $(\mathrm{cm})$ & $150.58 \pm 8.71$ & $154.77 \pm 8.39$ & $153.00 \pm 6.91$ & $152.92 \pm 7.78$ & 0.157 \\
\hline Physical Activity (METh/day) & $12.22 \pm 0.84$ & $12.61 \pm 0.85$ & $14.01 \pm 0.83$ & $14.01 \pm 0.84$ & 0.303 \\
\hline 85th $<$ BMI $^{3}<95$ th $(\%)$ & 0 & 17.6 & 16.7 & 40.0 & 0.0001 \\
\hline $\mathrm{BMI}>95$ th $(\%)$ & 2.9 & 0 & 5.6 & 11.4 & 0.0001 \\
\hline $\mathrm{WC}^{3}>75$ th $(\%)$ & 22.9 & 38.2 & 44.4 & 54.3 & 0.055 \\
\hline
\end{tabular}

${ }^{1}$ Values are mean \pm SD unless indicated.

${ }^{2} P$ values resulted from analysis of variance for quantitative variables and $\chi^{2}$ for qualitative variables.

${ }^{3}$ BMI: body mass index; WC: waist circumference.

and MET is the metabolic equivalent extracted from reference table [19]

\section{Statistical Analysis}

We used Nutritionist IV to analyze dietary intakes. SPSS software (version 12) was used to conduct the statistical analysis. Normal distribution was evaluated by Kolmogorov-Smirnov test, histogram graph, and p-p plot graph.

Fast food consumption was reported in quartiles. Cut points for fast food quartiles were 1st: <51.8, 2nd: 51.9100.7, 3rd: 100.8-214.9, 4th: $>215 \mathrm{~g} /$ week. Chi-square test was used for evaluating the prevalence of overweight, obesity, and abdominal obesity across fast food quartiles.

To compare the variations of continuous variables across quartiles of fast food intake, we used analysis of covariance (ANCOVA) which was adjusted for energy intake. Then estimated marginal means were gathered as energy-adjusted means. Partial correlation was used to assess the association between fast food intake, blood pressure, and anthropometric measurements. Energy intake was adjusted in the models.

\section{Results}

Demographic characteristics of adolescents across the quartiles of fast food consumption are shown in Table 1. There were no significant differences in age, height, physical activity, and abdominal obesity between quartiles of fast food consumption. The prevalence of overweight and obesity was higher in the upper quartiles of fast food intake.

Table 2 shows the energy-adjusted (except for energy intake) distribution of nutrients intake across the quartiles of the fast food consumption. Those in the highest quartile of fast food consumption had more energy intake and consumed more amount of protein, carbohydrate, fat, saturated fatty acid, and vitamin C. There were no significant differences regarding other nutrient intakes across quartiles of fast food intake.

Values regarding the energy-adjusted NARs were demonstrated in Table 3. The results showed that individuals in the highest quartiles of fast food intake had significantly lower NARs for vitamin $B_{1}$, phosphorus, selenium, and vitamin $B_{2}$
$(P=0.008, P=0.025, P<0.001, P=0.012$ resp. $)$ and higher NAR for vitamin C $(P=0.018)$. There was no significant association between fast food consumption and other NARs.

The mean of energy density among quartiles of fast food consumption is provided in Figure 1. The energy density in the upper quartiles of fast food intake was significantly higher than lower quartiles $(P=0.022)$.

The correlation between BMI, waist circumference, and fast food consumption are shown in Figure 2. In the crude model (model 1), there were significant positive correlations between $\mathrm{BMI} /$ waist circumference and fast food intake $(P=$ 0.01 for both). Although energy adjustment (model 2) attenuated correlation coefficients, the correlations remained statistically significant.

The mean of the BMI and waist circumference across fast food quartiles are shown in Table 4 . Those in the highest quartile of fast food intake had higher BMI and waist circumference in crude model (model 1$)(P=0.001$ for both). Although the relationships between waist circumference and fast food consumption were disappeared after energy adjustment (model 2) $(P=0.103)$, the association between BMI and fast food intake was marginally significant $(P=0.058)$.

\section{Discussion}

The results of the present study, which was conducted among Iranian adolescents, showed a significant association between fast food consumption and higher BMI and waist circumference. The relationship between some nutrients intake such as protein, carbohydrate, SFA, and vitamin $\mathrm{C}$ and fast food consumption was also significant. According to the results, NARs for vitamin $B_{1}$, phosphorus, selenium, and vitamin $B_{2}$ were lower among those in the highest quartile of fast food consumption compared to lowest quartile. Adolescents in the highest quartile of fast food intake had the highest dietary energy density.

The general concept of fast food may be different in Iran in comparison to western countries. Some Iranian fast foods may be similar to US fast foods like hamburgers, but others may be different. Sausage, calbas, hamburger, and pizza are the most popular consumed fast food among Iranians [10]. 
TABLE 2: Energy-adjusted distribution of nutrient intake across quartiles of fast food consumption.

\begin{tabular}{|c|c|c|c|c|c|}
\hline \multirow[b]{2}{*}{ Variables } & \multicolumn{4}{|c|}{ Quartiles of fast food intake } & \multirow[b]{2}{*}{$P^{2}$} \\
\hline & $\begin{array}{c}\mathrm{Q}_{1} \\
{[<51.8 \mathrm{~g} / \text { week }] n=35}\end{array}$ & $\begin{array}{c}\mathrm{Q}_{2} \\
{[51.9-100.7 \mathrm{~g} / \text { week }] n=34}\end{array}$ & $\begin{array}{c}\mathrm{Q}_{3} \\
{[100.8-214.9 \mathrm{~g} / \text { week }] n=36}\end{array}$ & $\begin{array}{c}\mathrm{Q}_{4} \\
{[>215 \mathrm{~g} / \text { week }] n=35}\end{array}$ & \\
\hline $\begin{array}{l}\text { Energy intake } \\
(\mathrm{kcal})^{4}\end{array}$ & $1874.4 \pm 528.2$ & $2080.3 \pm 609.4$ & $2270.2 \pm 901.7$ & $3357.1 \pm 934.0$ & 0.001 \\
\hline Protein (g) & $80.0 \pm 18.9^{1}$ & $78.2 \pm 18.0$ & $71.4 \pm 18$ & $66.3 \pm 20.7$ & 0.033 \\
\hline Carbohydrate (g) & $360.5 \pm 49.1$ & $360.3 \pm 47.2$ & $353.4 \pm 46.8$ & $322.5 \pm 55.0$ & 0.021 \\
\hline Fat $(g)$ & $73.6 \pm 23$ & $75.5 \pm 22.7$ & $81.7 \pm 22.2$ & $98.5 \pm 26$ & 0.001 \\
\hline $\mathrm{SFA}^{3}(\mathrm{~g})$ & $21.9 \pm 7.7$ & $22.2 \pm 7.5$ & $24.3 \pm 7.8$ & $28.9 \pm 8.8$ & 0.011 \\
\hline Cholesterol (mg) & $195.4 \pm 93.4$ & $190.7 \pm 90.3$ & $157.6 \pm 88.8$ & $149.8 \pm 104.7$ & 0.155 \\
\hline Sodium (mg) & $2468.8 \pm 566.1$ & $2390.0 \pm 546.3$ & $2387.4 \pm 537.0$ & $2544.8 \pm 633.0$ & 0.647 \\
\hline Vitamin D $(\mu \mathrm{g})$ & $2.9 \pm 2.3$ & $2.4 \pm 2.2$ & $2.4 \pm 2.1$ & $2.2 \pm 2.5$ & 0.706 \\
\hline Vitamin C (mg) & $34.5 \pm 42.0$ & $49.2 \pm 40.8$ & $48.2 \pm 40.2$ & $72.2 \pm 47.3$ & 0.018 \\
\hline Folate $(\mu \mathrm{g})$ & $237.1 \pm 53.2$ & $227.0 \pm 51.3$ & $212.4 \pm 50.4$ & $225.9 \pm 59.7$ & 0.247 \\
\hline Potassium (mg) & $3223.9 \pm 952.4$ & $3313.8 \pm 918.8$ & $3183.8 \pm 900.0$ & $3338.3 \pm 1066.6$ & 0.895 \\
\hline Calcium (mg) & $1611.8 \pm 631.2$ & $1522.5 \pm 608.7$ & $1405.0 \pm 598.8$ & $1301.8 \pm 706.9$ & 0.290 \\
\hline Iron $(\mathrm{mg})$ & $9.8 \pm 2.2$ & $9.6 \pm 2.2$ & $9.0 \pm 2.1$ & $8.6 \pm 2.5$ & 0.169 \\
\hline Magnesium (mg) & $278.2 \pm 66.8$ & $287.1 \pm 64.1$ & $266.7 \pm 63.0$ & $253.3 \pm 74.5$ & 0.265 \\
\hline Zinc (mg) & $9.6 \pm 2.7$ & $9.6 \pm 2.6$ & $8.7 \pm 2.6$ & $8.3 \pm 3.1$ & 0.227 \\
\hline
\end{tabular}

${ }^{1}$ Values are mean \pm SD unless indicated.

${ }^{2} P$ values are resulted from multivariate analysis of variance.

${ }^{3}$ SFA: saturated fatty acid.

${ }^{4}$ Energy was not adjusted for energy intake.

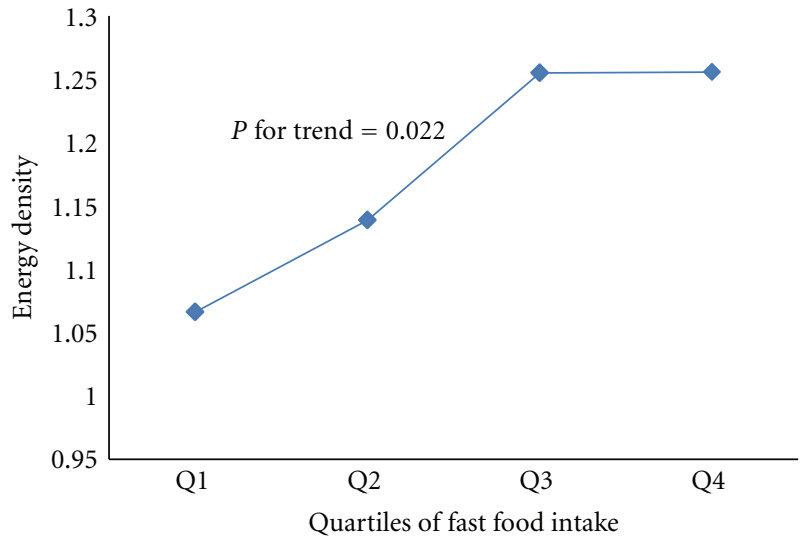

Figure 1: Dietary energy density across quartiles of fast food consumption.

These foods are not offered as a specific commercial brand; each outlet sells its production. So, we have different brands of the mentioned fast foods in Iran. Different producers provide sausages, calbas, hamburgers, and pizza. We have these products in the form of ready to eat in supermarkets and fast food restaurants in Iran. Rusk fish and rusk poultry are also available and usually consumed by fast food consumers. To prepare these foods, a slice of fish/poultry was imbued with rusk powder then it was inundated with oil for deep frying. So they are a rich source of fat, especially trans fatty acids as they are fried with partially hydrogenated vegetable oil [10]. Because of religious limitations, the content of

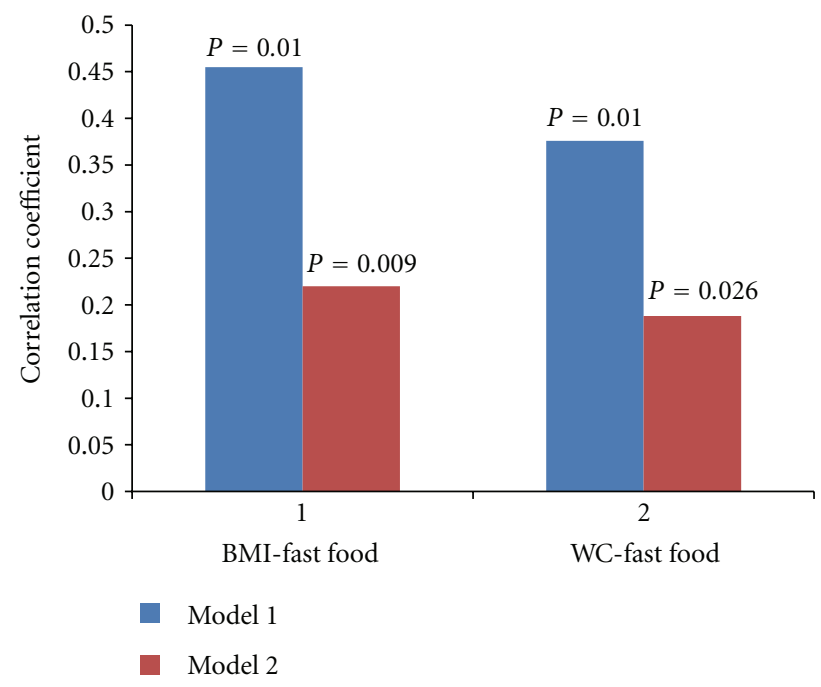

FIGURE 2: Correlation coefficients between BMI, waist circumference, and fast food consumption. Model 1: crude model, Model 2: energy-adjusted model.

Iranian sausage and calbas is free of pork meat and lard. Poultry, beef, and veal are used instead of pork meat.

In the present study, fast food consumers had higher BMI and higher waist circumference. Although Schröder et al. drew the same conclusion for the association between fast food consumption and BMI [20], the current study was conducted in adolescent girls but their study population in 
TABLE 3: Energy-adjusted distribution of nutrient adequacy ratio across fast food consumption quartiles.

\begin{tabular}{|c|c|c|c|c|c|}
\hline \multirow{3}{*}{ Variables } & \multicolumn{4}{|c|}{ Quartiles of fast food intake } & \multirow{3}{*}{$P^{2}$} \\
\hline & Q1 & Q2 & Q3 & Q4 & \\
\hline & {$[<51.8 \mathrm{~g} /$ week $] n=35$} & {$[51.9-100.7 \mathrm{~g} /$ week $] n=34$} & {$[100.8-214.9 \mathrm{~g} /$ week $] n=36$} & $\begin{array}{c}{[>215 \mathrm{~g} / \text { week }]} \\
n=35\end{array}$ & \\
\hline Iron/DRI ${ }^{\ddagger}$ & $1.237 \pm 0.28^{1}$ & $1.209 \pm 0.27$ & $1.131 \pm 0.27$ & $1.081 \pm 0.31$ & 0.169 \\
\hline Magnesium/DRI ${ }^{\ddagger}$ & $1.159 \pm 0.27$ & $1.196 \pm 0.26$ & $1.112 \pm 0.26$ & $1.055 \pm 0.31$ & 0.265 \\
\hline Zinc/DRI ${ }^{\ddagger}$ & $1.204 \pm 0.34$ & $1.201 \pm 0.33$ & $1.099 \pm 0.33$ & $1.038 \pm 0.39$ & 0.227 \\
\hline Manganese/DRI ${ }^{\dagger}$ & $1.626 \pm 0.49$ & $1.605 \pm 0.47$ & $1.462 \pm 0.46$ & $1.414 \pm 0.55$ & 0.278 \\
\hline Vitamin $\mathrm{A} / \mathrm{DRI}^{\ddagger}$ & $0.960 \pm 0.62$ & $1.006 \pm 0.60$ & $0.876 \pm 0.59$ & $1.117 \pm 0.69$ & 0.484 \\
\hline Vitamin $\mathrm{B}_{1} / \mathrm{DRI}^{\ddagger}$ & $1.596 \pm 0.28$ & $1.598 \pm 0.27$ & $1.520 \pm 0.27$ & $1.356 \pm 0.31$ & 0.008 \\
\hline Vitamin $\mathrm{B}_{3} / \mathrm{DRI}^{\ddagger}$ & $1.170 \pm 0.31$ & $1.287 \pm 0.30$ & $1.233 \pm 0.30$ & $1.171 \pm 0.35$ & 0.337 \\
\hline Folate/DRI ${ }^{\ddagger}$ & $0.791 \pm 0.17$ & $0.757 \pm 0.17$ & $0.708 \pm 0.16$ & $0.753 \pm 0.20$ & 0.247 \\
\hline Pantothenic/DRI ${ }^{\dagger}$ & $0.978 \pm 0.29$ & $0.943 \pm 0.28$ & $0.897 \pm 0.28$ & $0.808 \pm 0.33$ & 0.201 \\
\hline Vitamin $\mathrm{C} / \mathrm{DRI}^{\ddagger}$ & $0.769 \pm 0.94$ & $1.094 \pm 0.90$ & $1.073 \pm 0.89$ & $1.605 \pm 1.05$ & 0.018 \\
\hline Vitamin $\mathrm{K} / \mathrm{DRI}^{\dagger}$ & $1.127 \pm 1.04$ & $1.056 \pm 1.00$ & $0.686 \pm 0.99$ & $0.939 \pm 1.16$ & 0.266 \\
\hline Potassium/DRI ${ }^{\dagger}$ & $0.716 \pm 0.21$ & $0.736 \pm 0.20$ & $0.708 \pm 0.19$ & $0.742 \pm 0.23$ & 0.895 \\
\hline Calcium/DRI ${ }^{\dagger}$ & $1.240 \pm 0.48$ & $1.171 \pm 0.46$ & $1.081 \pm 0.46$ & $1.001 \pm 0.54$ & 0.290 \\
\hline Phosphorus/DRI ${ }^{\ddagger}$ & $1.619 \pm 0.40$ & $1.508 \pm 0.39$ & $1.393 \pm 0.39$ & $1.300 \pm 0.45$ & 0.025 \\
\hline Cupper/DRI ${ }^{\ddagger}$ & $1.793 \pm 0.40$ & $1.764 \pm 0.39$ & $1.661 \pm 0.39$ & $1.511 \pm 0.46$ & 0.064 \\
\hline Selenium/DRI ${ }^{\ddagger}$ & $1.671 \pm 0.45$ & $1.485 \pm 0.43$ & $1.345 \pm 0.43$ & $1.012 \pm 0.50$ & 0.000 \\
\hline Vitamin $\mathrm{B}_{2} / \mathrm{DRI}^{\ddagger}$ & $3.285 \pm 0.95$ & $3.049 \pm 0.92$ & $2.762 \pm 0.91$ & $2.453 \pm 1.07$ & 0.012 \\
\hline Vitamin $\mathrm{B}_{6} / \mathrm{DRI}^{\ddagger}$ & $1.098 \pm .032$ & $1.213 \pm 0.31$ & $1.164 \pm .051$ & $1.253 \pm 0.36$ & 0.282 \\
\hline Vitamin $\mathrm{B}_{12} / \mathrm{DRI}^{\ddagger}$ & $1.662 \pm 0.67$ & $1.573 \pm 0.65$ & $1.464 \pm .107$ & $1.489 \pm 0.75$ & 0.618 \\
\hline Vitamin D/DRI $^{\dagger}$ & $0.587 \pm 0.46$ & $0.491 \pm 0.44$ & $0.491 \pm .073$ & $0.454 \pm 0.52$ & 0.706 \\
\hline
\end{tabular}

${ }^{1}$ Values are mean \pm SD unless indicated.

${ }^{2} P$ values are resulted from multivariate analysis of variance.

${ }^{\dagger}$ Adequate intake is considered as DRI.

${ }^{\ddagger}$ Recommended dietary allowance is considered as DRI.

TABLE 4: Body mass index and waist circumference trend across fast food quartiles.

\begin{tabular}{|c|c|c|c|c|c|}
\hline \multicolumn{6}{|c|}{ Quartiles of fast food intake } \\
\hline Variables & $\begin{array}{c}\mathrm{Q}_{1} \\
{[<51.8 \mathrm{~g} / \text { week }] n=35}\end{array}$ & $\begin{array}{c}\mathrm{Q}_{2} \\
{[51.9-100.7 \mathrm{~g} / \text { week }] n=34}\end{array}$ & $\begin{array}{c}\mathrm{Q}_{3} \\
{[100.8-214.9 \mathrm{~g} / \text { week }] n=36}\end{array}$ & $\begin{array}{c}\mathrm{Q}_{4} \\
{[>215 \mathrm{~g} / \text { week }] n=35}\end{array}$ & $P^{1}$ \\
\hline \multicolumn{6}{|l|}{ Model $1^{4}$} \\
\hline $\mathrm{BMI}^{2}$ & $18.3 \pm 2.6^{3}$ & $19.3 \pm 2.6$ & $19.6 \pm 3.4$ & $22.3 \pm 3.2$ & 0.001 \\
\hline $\mathrm{WC}^{2}$ & $64.2 \pm 7.2$ & $68.7 \pm 9.2$ & $68.9 \pm 8.3$ & $74.2 \pm 9.5$ & 0.001 \\
\hline \multicolumn{6}{|l|}{ Model $2^{5}$} \\
\hline BMI & $18.7 \pm 2.9$ & $19.8 \pm 2.8$ & $19.8 \pm 2.8$ & $21.0 \pm 3.3$ & 0.058 \\
\hline WC & $65.7 \pm 8.8$ & $69.6 \pm 8.5$ & $69.3 \pm 8.4$ & $71.4 \pm 9.9$ & 0.103 \\
\hline
\end{tabular}

${ }^{1} P$ values are computed by multivariate analysis of variance [MANOVA].

${ }^{2}$ BMI: body mass index; WC: waist circumference.

${ }^{3}$ Values were presented as mean $\pm \mathrm{SD}$.

${ }^{4}$ Model 1: crude model.

${ }^{5}$ Model 2: energy-adjusted model.

Schröder et al. was Spanish subjects aged 25-74 years old. Another study indicated a positive association between fast food intake and BMI in both cross-sectional and longitudinal analysis among young adults [21]. Probable hypothesis is that more fast food consumption is associated with more energy intake from non-fast-food and fast food sources [20].
One study exhibited that visiting fast food outlets increased the amount of sugar sweetened beverages intake [22]. For instance, a significant direct association between fast food intake and sugar sweetened beverages (SSB) has been reported [23]. Beyond the high sugar content of SSBs, these kinds of beverages may decrease satiety and increased subsequent 
food intake [21]. Such findings may explain the mechanism of the relationship between increased energy intake from non-fast-food sources and fast food consumption. The results of the present study revealed that association between fast food intake and obesity was not totally mediated by energy intake. Fat content of fast foods might also have a role in this association. Iranian fast foods are rich source of trans fatty acid and SFAs [10]. Studies reported the link between trans fatty acids intake and obesity [24].

The relevance between dietary quality and fast food consumption was evaluated in current study by some indices. The energy-adjusted distribution of nutrients across quartiles of fast food consumption showed that adolescents in the highest quartile consumed more amount of protein, carbohydrate, fat, saturated fatty acid, and vitamin C. Previous studies have illustrated that saturated fatty acid content of Iranian fast food is high [10]. Recent data showed that more fast food consumption was related to higher fats and processed meats intake [25]. High amount of processed meat in different kinds of fast foods can explain the reported positive relationship between fast food consumption and protein intake. Consumption of fast foods is almost accompanied with vegetable salads (e.g., lettuce and cruciferous), pepper, and tomato sauces. On the other hand, fruit and vegetables are the best sources of vitamin C [26]. So higher vitamin C intake may result from this accompaniment. In the present study dietary quality was inversely associated with fast food intake because NARs for vitamin B1, phosphorus, selenium, and vitamin B2 decreased across quartiles of fast food consumption. White bread is another food consumed along with fast foods in Iranian dietary habits. Thiamine content of white bread is less than whole wheat bread [27]. Moreover, the conversion of phytic acid to its soluble form in unleavened bread commonly consumed among Iranians is less than leavened ones [28]. So the content of the dietary phosphorus in these kind of breads have been decreased. As we know, dairy products are considered as vitamin- $\mathrm{B}_{2}$-rich foods [29]. On the other hand, Dough, an Iranian traditional beverage derived from yoghurt, is usually replaced with SSBs when subjects consume fast food. So, lower vitamin $\mathrm{B}_{2}$ intake can also be predicted.

Dietary energy density, another index for dietary quality, showed a statistical significant association with fast food intake. Fast foods are considered as energy dense foods and similar relationship between dietary energy density and fast food intake was reported in previous studies $[20,30]$.

In the current study, we have disclosed a significant energy-adjusted positive correlation coefficients between obesity-related anthropometric variables, that is, $\mathrm{BMI}$ and waist circumference and fast food consumption. A positive association between the frequency of fast food intake and body weigh after 15-year followup has also been reported from a prospective study [21]. Cross-sectional studies have reported a same association for fast food consumption and total energy intake [31]. Frying oils and partial hydrogenated vegetable oils (PHVO) rich in trans fatty acids are used for preparing fast foods in Iran. Previous study showed that consumption of $\mathrm{PHVO}$ is a risk factor for systemic inflammation, cardiovascular disease [32], and obesity [33].
The energy density of the fast foods may explain this correlation [34]. The energy density of fast foods was higher than the recommended energy density in a healthy diet $(1100 \mathrm{~kJ} / 100 \mathrm{~g}$ versus $525 \mathrm{~kJ} / 100 \mathrm{~g})$ [33]. One study suggested that we should choose healthier fast foods with lower energy, fat content, and energy density rather than traditional fast foods [35]. Low-energy dense diets like high fiber diets could reduce weight and waist circumference [36]. However, highenergy dense diets could increase the prevalence of obesity and abdominal adiposity [37].

These results were affected by some limitations. Due to cross-sectional nature of the present study, causal relationship could not be concluded [38]. So, prospective studies should be run in this population for more reliable data. Moreover, we used a FFQ consist of 53 food items for dietary assessment. Although the validity and reliability of this FFQ had been assessed, the variation of food choices might be more than 53 food items. Furthermore, our FFQ was not designed to assess the SSBs. Simultaneous evaluation of the SSBs intake and fast food consumption may disclose more aspects of fast food dietary pattern. Small sample size is another limitation. However the sample was drawn through well-conducted random sampling and the study finding showed statistically significant associations. However, data from large sample size studies are more credible.

Several strength points should be addressed regarding the present study. Dietary intake was assessed by a validated FFQ. There are few epidemiological studies about the association between fast food intake, obesity, and dietary quality among this population. Evaluating the diet quality by several indices, that is, NARs, energy density and nutrient intakes, is another strength point.

In conclusion there is a relationship between fast food consumption, obesity, and diet quality indices among Iranian adolescents.

\section{Conflict of Interests}

The authors have no conflict of interests.

\section{Authors' Contribution}

N. Omrani and M. Mirseifinezhad participated in data collection. M. H. Rouhani did more analysis and drafted the paper. L. Azadbakht and A. Esmaillzadeh designed and supervised the study and edited the draft of the paper.

\section{Acknowledgments}

Isfahan University of Medical Sciences supported this paper. The authors express our thankfulness to participants.

\section{References}

[1] C. M. Apovian, "The causes, prevalence, and treatment of obesity revisited in 2009: what have we learned so far?" American Journal of Clinical Nutrition, vol. 91, no. 1, pp. 277S-279S, 2010. 
[2] L. Azadbakht and A. Esmaillzadeh, "Dietary diversity score is related to obesity and abdominal adiposity among Iranian female youth," Public Health Nutrition, vol. 14, no. 1, pp. 6269, 2011.

[3] L. Azadbakht, P. Mirmiran, N. Shiva, and F. Azizi, "General obesity and central adiposity in a representative sample of Tehranian adults: prevalence and determinants," International Journal for Vitamin and Nutrition Research, vol. 75, no. 4, pp. 297-304, 2005.

[4] A. M. G. Cali and S. Caprio, "Obesity in children and adolescents," Journal of Clinical Endocrinology and Metabolism, vol. 93, no. 11, pp. s31-s36, 2008.

[5] R. Kelishadi, G. Ardalan, R. Gheiratmand et al., "Thinness, overweight and obesity in a national sample of Iranian children and adolescents: CASPIAN Study," Child, vol. 34, no. 1, pp. 44-54, 2008.

[6] M. Maddah and B. Nikooyeh, "Obesity among iranian adolescent girls: location of residence and parental obesity," Journal of Health, Population and Nutrition, vol. 28, no. 1, pp. 61-66, 2010.

[7] S. K. Kapoor and K. Anand, "Nutritional transition: a public health challenge in developing countries," Journal of Epidemiology and Community Health, vol. 56, no. 11, pp. 804-805, 2002.

[8] B. M. Popkin, "Contemporary nutritional transition: determinants of diet and its impact on body composition," Proceedings of the Nutrition Society, vol. 178, no. 2, pp. 387-397, 2005.

[9] S. Asgary, B. Nazari, N. Sarrafzadegan et al., "Evaluation of fatty acid content of some Iranian fast foods with emphasis on trans fatty acids," Asia Pacific Journal of Clinical Nutrition, vol. 70, no. 1, pp. 82-91, 2011.

[10] E. Isganaitis and R. H. Lustig, "Fast food, central nervous system insulin resistance, and obesity," Arteriosclerosis, Thrombosis, and Vascular Biology, vol. 25, no. 12, pp. 2451-2462, 2005.

[11] P. H. Chiang, M. L. Wahlqvist, M. S. Lee et al., "Fastfood outlets and walkability in school neighborhoods predict fatness in boys and height in girls: a Taiwanese population study," Public Health Nutrition, vol. 14, no. 9, pp. 1601-1609, 2011.

[12] D. Demory-Luce, "Fast food and children and adolescents: implications for practitioners," Clinical Pediatrics, vol. 44, no. 4, pp. 279-288, 2005.

[13] S. Paeratakul, D. P. Ferdinand, C. M. Champagne, D. H. Ryan, and G. A. Bray, "Fast-food consumption among US adults and children: dietary and nutrient intake profile," Journal of the American Dietetic Association, vol. 103, no. 10, pp. 1332-1338, 2003.

[14] L. Azadbakht, P. Mirmiran, F. Hosseini, and F. Azizi, "Diet quality status of most Tehranian adults needs improvement," Asia Pacific Journal of Clinical Nutrition, vol. 14, no. 2, pp. 163168, 2005.

[15] A. Esmaillzadeh and L. Azadbakht, "Food intake patterns may explain the high prevalence of cardiovascular risk factors among Iranian women," Journal of Nutrition, vol. 138, no. 8, pp. 1469-1475, 2008.

[16] "Dietary reference intakes (DRIs): recommended intakes for individuals, vitamin/mineral," in Krause's Food \& Nutrition Therapy, S. Escott-Stump and L. Mahan, Eds., Saunders Elsevier, Philadelphia, Pa, USA, 12th edition, 2008.

[17] J. H. Ledikwe, H. M. Blanck, L. K. Khan et al., "Dietary energy density determined by eight calculation methods in a nationally representative United States population," Journal of Nutrition, vol. 135, no. 2, pp. 273-278, 2005.
[18] Y. Liu, G. Tong, W. Tong, L. Lu, and X. Qin, "Can body mass index, waist circumference, waist-hip ratio and waist-height ratio predict the presence of multiple metabolic risk factors in Chinese subjects?" BMC Public Health, vol. 11, article 35, 2011.

[19] B. E. Ainsworth, W. L. Haskell, M. C. Whitt et al., "Compendium of physical activities: an update of activity codes and MET intensities," Medicine and Science in Sports and Exercise, vol. 32, no. 9, pp. S498-S504, 2000.

[20] H. Schröder, M. Fito, and M. I. Covas, "Association of fast food consumption with energy intake, diet quality, body mass index and the risk of obesity in a representative Mediterranean population," British Journal of Nutrition, vol. 98, no. 6, pp. 1274-1280, 2007.

[21] M. A. Pereira, A. I. Kartashov, C. B. Ebbeling et al., "Fastfood habits, weight gain, and insulin resistance (the CARDIA study): 15-year prospective analysis," The Lancet, vol. 365, no. 9453, pp. 36-42, 2005.

[22] J. L. Wiecha, D. Finkelstein, P. J. Troped, M. Fragala, and K. E. Peterson, "School vending machine use and fast-food restaurant use are associated with sugar-sweetened beverage intake in youth," Journal of the American Dietetic Association, vol. 106, no. 10, pp. 1624-1630, 2006.

[23] J. R. Sharkey, C. M. Johnson, and W. R. Dean, "Nativity is associated with sugar-sweetened beverage and fast-food meal consumption among mexican-origin women in Texas border colonias," Nutrition Journal, vol. 30, no. 10, p. 101, 2011.

[24] S. E. Dorfman, D. Laurent, J. S. Gounarides et al., "Metabolic implications of dietary trans-fatty acids," Obesity, vol. 17, no. 6, pp. 1200-1207, 2009.

[25] L. V. Moore, A. V. Diez-Roux, J. A. Nettleton et al., "Fast-food consumption, diet quality, and neighborhood exposure to fast food: the multi-ethnic study of atherosclerosis," American Journal of Epidemiology, vol. 170, no. 1, pp. 29-36, 2009.

[26] M. L. Gallathe, "The nutrients and their metabolism," in Krause's Food \& Nutrition Therapy, S. Escott-Stump and L. Mahan, Eds., p. 96, Saunders Elsevier, Philadelphia, Pa, USA, 12th edition, 2008.

[27] F. Batifoulier, M. A. Verny, E. Chanliaud, C. Rémésy, and C. Demigné, "Variability of B vitamin concentrations in wheat grain, milling fractions and bread products," European Journal of Agronomy, vol. 25, no. 2, pp. 163-169, 2006.

[28] M. L. Gallathe, "The nutrients and their metabolism," in Krause's Food \& Nutrition Therapy, S. Escott-Stump and L. Mahan, Eds., p. 109, Saunders Elsevier, Philadelphia, Pa, USA, 12th edition, 2008.

[29] M. L. Gallathe, "The nutrients and their metabolism," in Krause's Food \& Nutrition Therapy, S. Escott-Stump and L. Mahan, Eds., p. 85, Saunders Elsevier, Philadelphia, Pa, USA, 12th edition, 2008.

[30] S. A. Bowman and B. T. Vinyard, "Fast food consumption of U.S. adults: impact on energy and nutrient intakes and overweight status," Journal of the American College of Nutrition, vol. 23, no. 2, pp. 163-168, 2004.

[31] S. A. Bowman, S. L. Gortmaker, C. B. Ebbeling, M. A. Pereira, and D. S. Ludwig, "Effects of fast-food consumption on energy intake and diet quality among children in a National Household Survey," Pediatrics, vol. 113, no. 1 I, pp. 112-118, 2004.

[32] A. Esmaillzadeh and L. Azadbakht, "Home use of vegetable oils, markers of systemic inflammation, and endothelial dysfunction among women," American Journal of Clinical Nutrition, vol. 88, no. 4, pp. 913-921, 2008. 
[33] K. Kavanagh, K. L. Jones, J. Sawyer et al., "Trans fat diet induces abdominal obesity and changes in insulin sensitivity in monkeys," Obesity, vol. 15, no. 7, pp. 1675-1684, 2007.

[34] A. M. Prentice and S. A. Jebb, "Fast foods, energy density and obesity: a possible mechanistic link," Obesity Reviews, vol. 4, no. 4, pp. 187-194, 2003.

[35] E. Brindal, P. Mohr, C. Wilson, and G. Wittert, "Obesity and the effects of choice at a fast food restaurant," Obesity Research and Clinical Practice, vol. 2, no. 2, pp. 111-117, 2008.

[36] A. Esmaillzadeh and L. Azadbakht, "Dietary energy density and the metabolic syndrome among Iranian women," European Journal of Clinical Nutrition, vol. 65, no. 5, pp. 598-605, 2011.

[37] L. Azadbakht, P. J. Surkan, A. Esmaillzadeh, and W. C. Willett, "The dietary approaches to stop hypertension eating plan affects C-reactive protein, coagulation abnormalities, and hepatic function tests among type 2 diabetic patients," Journal of Nutrition, vol. 141, no. 6, pp. 1083-1088, 2011.

[38] C. J. Mann, "Observational research methods. Research design II: cohort, cross sectional, and case-control studies," Emergency Medicine Journal, vol. 20, no. 1, pp. 54-60, 2003. 


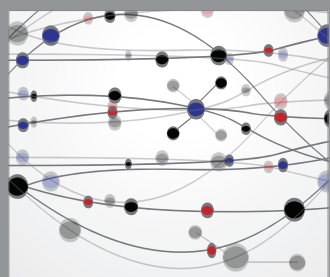

The Scientific World Journal
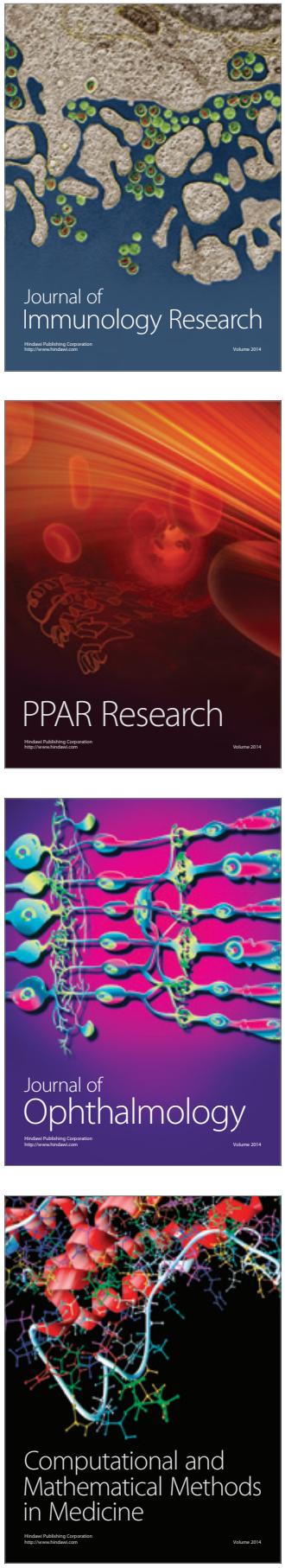

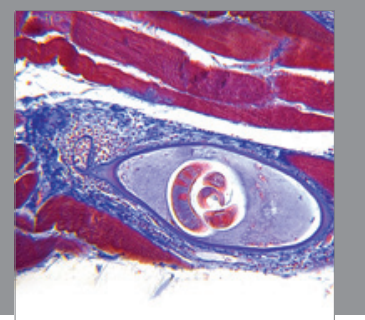

Gastroenterology

Research and Practice
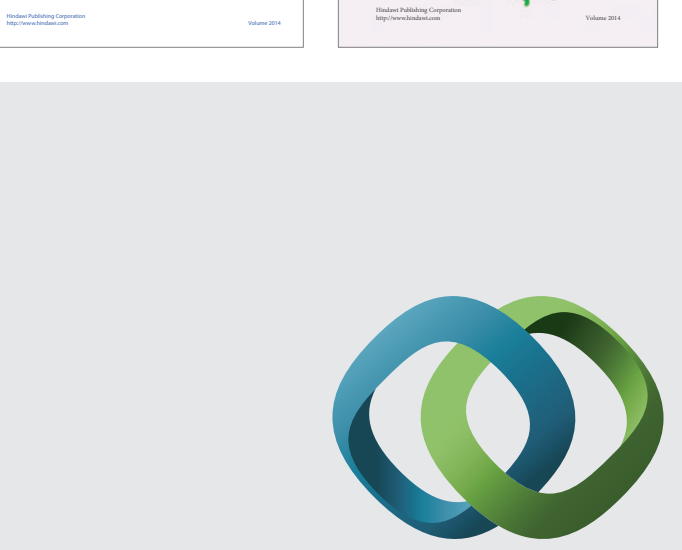

\section{Hindawi}

Submit your manuscripts at

http://www.hindawi.com
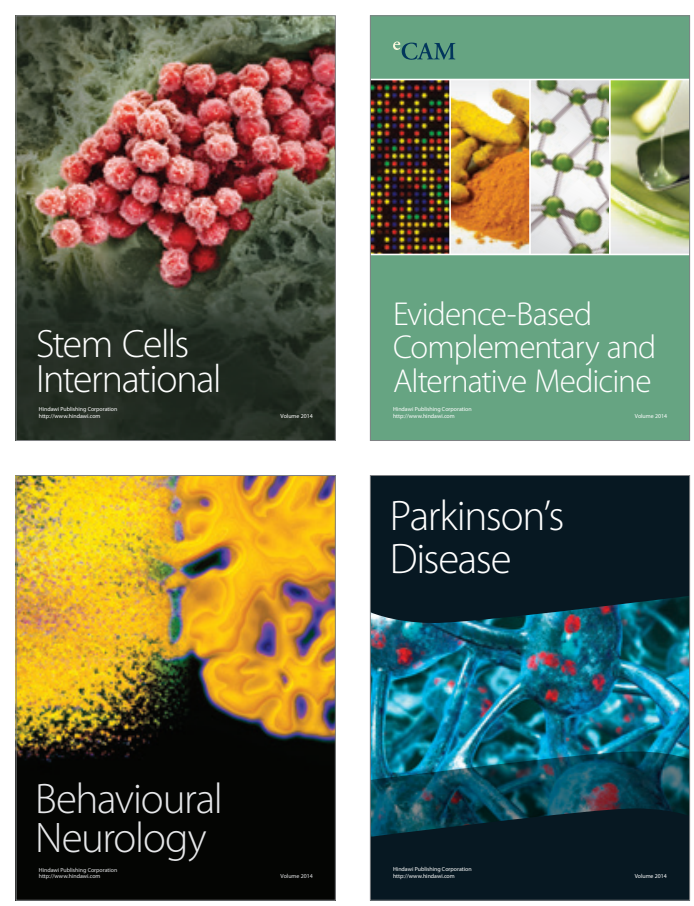

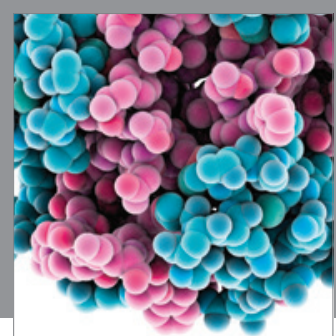

Journal of
Diabetes Research

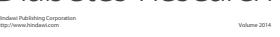

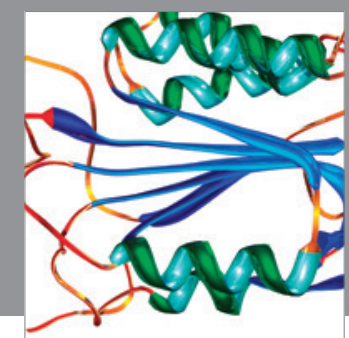

Disease Markers
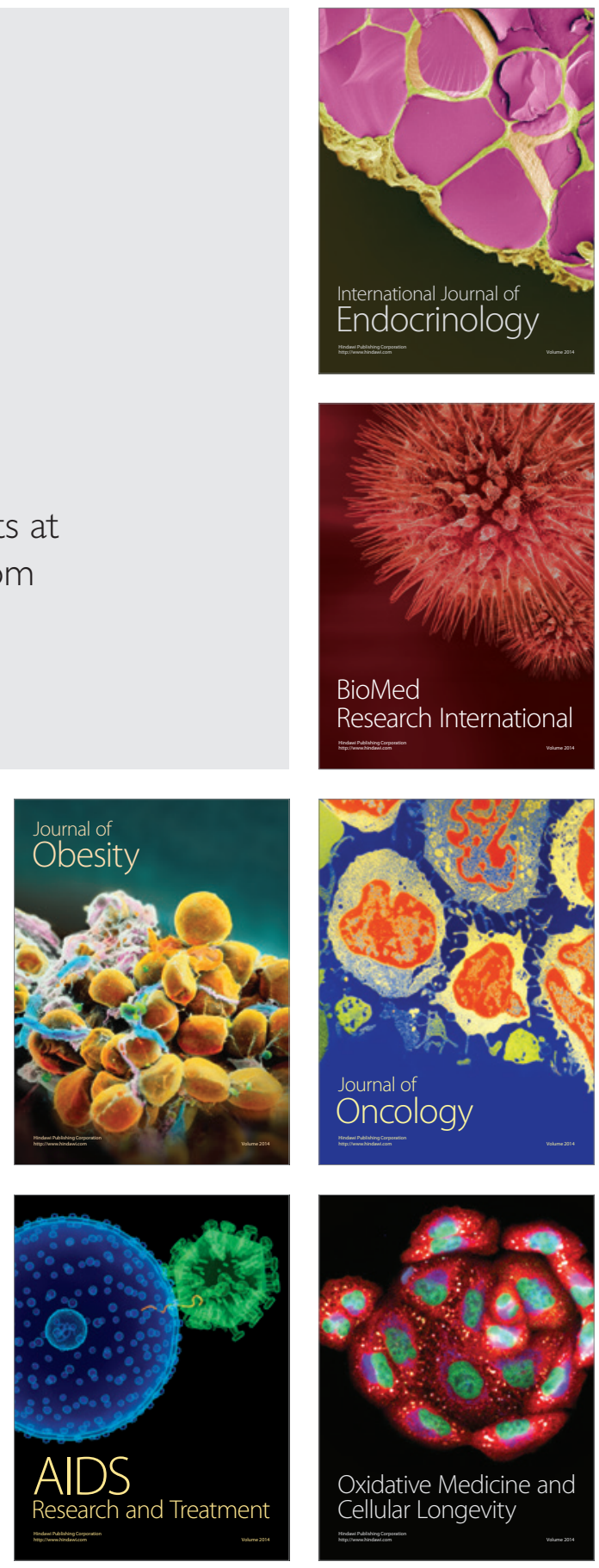